\title{
Neurological complications of pertussis inoculation
}

\author{
M. KULENKAMPFF, „ J. S. SCHWARTZMAN, $†$ and J. WILSON \\ From The Hospital for Sick Children, Great Ormond Street, London
}

\begin{abstract}
Kulenkampff, M., Schwartzman, J. S., and Wilson, J. (1974). Archives of Disease in Childhood, 49, 46. Neurological complications of pertussis inoculation. Findings are presented in 36 children, seen in the past 11 years, who are believed to have suffered from neurological complications of pertussis inoculation (given as triple vaccine). The clustering of complications in the first 24 hours after inoculation suggests a causal rather than a coincidental relation. Possible contributory factors were present in one-third of patients studied and support the view that idiosyncratic features are present in the patients, not the vaccine. A prospective review is urged. It is recommended that pertussis vaccine should not be given to patients with a history of fits, or a family history of fits in first-degree relatives, or to those who have had a reaction to previous inoculations, those who have had recent intercurrent infection, or those with presumed neurological deficit.
\end{abstract}

Inoculation against pertussis has been for several decades an accepted prophylactic procedure to reduce mortality and morbidity of this infectious disease, especially in very young children. Several papers have considered what is the optimum immunization schedule which would (a) protect the child at an age when most at risk from complications, (b) offer immunization at an age when an adequate immune response can be achieved, and (c) achieve a satisfactory level of 'herd' immunity (Sako et al., 1945; Miller, 1951; Vahlquist, Hesselvik, and Ericsson, 1954; Provenzano, Wetterlow, and Ipsen, 1959; Goddard, 1964; Ehrengut, 1966).

There have been, too, reports about neurological complications after pertussis immunization. The first, about two fatal cases, came from Denmark (Madsen, 1933) and was soon followed by observations in other countries (Globus and Kohn, 1949; Byers and Moll, 1948; Sutherland, 1953; Miller and Stanton, 1954).

The severe neurological complications orginally seen after pertussis inoculation and after the administration of the combined vaccines that are widely used (mainly combined diphtheria, pertussis, and tetanus vaccine-DPT) are identical (Miller and Stanton, 1954; Berg, 1958; Hopper, 1961). The clinical picture does not closely resemble any of the reactions to other vaccines given singly, but is

\footnotetext{
Received 11 July 1973.

*Present address : Department of Child Life and Health. Sciennes Road, Edinburgh.

†Present address: Sao Paulo, Brazil.
}

similar to complications of the disease itself. The $\vec{\varphi}$ pertussis component is therefore regarded as $I$ containing a potentially encephalopathic factor.

The frequency of complications of DPT inoculation in the U.K. is unknown. In the Medical Research Council trials published in 1956, convulsions in the first 72 hours after inoculation were reported with frequencies of 1 in 2500 in 1948-1951, and 1 in 4000 for 1951-1954; the report concluded that this frequency did not exceed the expected natural occurrence rate in the age groups under review-an assumption of dubious logicand dismissed as coincidental those occurring after 72 hours. Strøm $(1960,1967)$ investigated various encephalopathic complications (convulsions, 'shock', and meningism) occurring up to 7 days after inoculation in Swedish children and found 1 in 6000 in the period 1955-1958, and 1 in 3600 in 1950-1965. Strøm's papers aroused strong criticism, especially among his colleagues, one of the arguments being $\frac{T}{0}$ that Strøm did not exclude cases with pre-existing abnormalities and therefore overestimated both the o frequency of complications and their sequelae. While this argument has some validity when estimating frequency and severity of sequelae, it $\omega$ should not be used to exclude immediate complications from consideration. Indeed, his study $\varrho$ may lead to valuable information about factors predisposing to complications.

Although it is widely assumed that children with, for example, pre-existing neurodevelopmental abnormalities are especially liable to encephalopathic 
complications of both naturally occurring infections and inoculation, the evidence is very incomplete and conclusions are controversial, especially with respect to inoculation (Cockburn, 1951; Köng, 1953; Halpern and Halpern, 1955; Berg, 1958).

A series of children believed to have reacted adversely to DPT inoculation has been studied retrospectively in an attempt to clarify these issues.

\section{Patients}

Between January 1961 and December 1972 approximately 50 children have been seen at The Hospital for Sick Children, London, because of neurological illness thought to be due to DPT inoculation. Several children with screaming and fever during the first 24 hours have been excluded from the study because of their benign outcome. The majority of the remainder, whose ages ranged from 3 months to 7 years were referred months or years after the acute episode, usually because of problems related to the sequelae, and are therefore a selected group. There were 36 children in whom there was adequate data on the timing, and only those neurological illnesses occurring up to 14 days after DPT inoculation were included.

\section{Results}

Sex distribution. There were 13 boys and 23 girls.

Age at immunization. Findings are shown in Table I, and reflect the Department of Health's recommendations.

TABLE I

Age of infants having major complications of DPT inoculation

\begin{tabular}{c|c}
\hline $\begin{array}{c}\text { Age at reaction } \\
(\mathrm{mth})\end{array}$ & No. of patients \\
\hline 3 & 9 \\
$4-6$ & 19 \\
$7-12$ & 1 \\
$13-18$ & 7 \\
\hline Total & 36
\end{tabular}

DPT, combined diphtheria, pertussis, and tetanus vaccine.

Interval and number of inoculations. The interval between inoculation and the occurrence of complications, together with the number of the provocative inoculations are shown in Table II. Among the patients presenting in the earlier years were those inoculated at three successive monthly intervals. Lately, only two injections were given at monthly intervals followed by a 'booster' DPT inoculation several months later.
TABLE II

Interval between inoculation and reaction

\begin{tabular}{|c|c|c|c|c|}
\hline & \multicolumn{4}{|c|}{ Interval } \\
\hline & $0-24 \mathrm{hr}$ & $1-7 \mathrm{dy}$ & 1-2 wk & Total \\
\hline $\begin{array}{l}\text { Reaction to: } \\
\text { 1st DPT } \\
\text { 2nd DPT } \\
\text { 3rd DPT } \\
\text { Booster DPT }\end{array}$ & $\begin{array}{r}10 \\
7 \\
5 \\
2\end{array}$ & $\begin{array}{l}2 \\
6 \\
1 \\
-\end{array}$ & $\frac{1}{1}$ & $\begin{array}{r}13 \\
14 \\
6 \\
3\end{array}$ \\
\hline Total & 24 & 9 & 3 & 36 \\
\hline
\end{tabular}

DPT, combined diphtheria, pertussis, and tetanus vaccine.

Complications. 32 infants and young children convulsed; their clinical features, which are similar, are summarized in Table III. No laboratory data

TABLE III

Clinical features in 32 infants who convulsed

\begin{tabular}{|c|c|c|c|}
\hline \multirow{2}{*}{ Clinical abnormality } & \multicolumn{3}{|c|}{ Interval } \\
\hline & $0-24 \mathrm{hr}$ & $1-7 \mathrm{dy}$ & $1-2 \mathrm{wk}$ \\
\hline $\begin{array}{l}\text { Convulsions } \\
\text { Infantile spasms } \\
\text { Screaming and } \\
\text { irritability } \\
\text { Vomiting } \\
\text { Continuing } \\
\text { unconsciousness } \\
\text { Coincident infection }\end{array}$ & $\begin{array}{r}23 \\
3 \\
5 \\
- \\
5 \\
1\end{array}$ & $\begin{array}{l}7 \\
1 \\
1 \\
4 \\
3 \\
1\end{array}$ & $\begin{array}{l}2 \\
- \\
1 \\
1 \\
2\end{array}$ \\
\hline
\end{tabular}

are available because the children were all seen after the acute episode. One child was exceptional in that she had transient blindness after recovering from a fit; she was later discovered to be suffering from a progressive cerebral degeneration, like her twin sister.

The 4 children who did not convulse include the identical twin of the infant above. She vomited 4 days after her second DPT inoculation at 15 months, and developed severe cortical blindness and optic atrophy. She died in status epilepticus at 21 months of age after a progressive course.

A second child who did not convulse developed a hemiparesis 2 weeks after a second DPT inoculation at 6 months. This could have been coincidental.

A third child became ill with fever, malaise, and swelling at the site of inoculation, 24 hours after a third DPT injection at 6 months. Though the constitutional upset improved, she continued to vomit. A plaster spica for congenitally dislocated hips was removed, with improvement of the vomiting, but 12 days after inoculation she became 
miserable, and developed a hemiparesis, left ptosis, and gaze palsy. Spinal fluid 16 days after inoculation contained 6 polymorphs $/ \mathrm{mm}^{3}$ and $20 \mathrm{mg}$ protein $/ 100 \mathrm{ml}$. After 3 weeks she had an asymmetric double hemiparesis, multiple cranial nerve palsies, and was unrousable. At this stage treatment with ACTH (40 units daily), and later prednisone (15 $\mathrm{mg}$ daily), was started, with rapid improvement. Subsequently, over several months she made an apparently complete recovery. Now, 6 years later, she is progressing well at an ordinary school, and appears normal in every way.

The fourth child was given a second DPT inoculation and oral polio vaccine at 6 months of age, on the second day of an acute upper respiratory tract infection. 10 days later she suddenly developed flaccid weakness of upper and lower limbs, with respiratory embarrassment. Spinal fluid examined within 12 hours of onset contained $40 \mathrm{mg}$ protein $/ 100 \mathrm{ml}$ and 60 white cells (predominantly polymorphs) per $\mathrm{mm}^{3}$. Cytomegalovirus was cultured from her urine (Dr. W. C. Marshall). At necropsy, after acute respiratory embarrassment 6 weeks later, she had an extensive necrotizing lesion extending from the midcervical to the upper dorsal segments of the spinal cord (Professor K. Simpson).

Sequelae. Two children (previously mentioned) died within 6 months of the onset of complications; in only one did inoculation seem directly contributory.

Four children recovered completely. 22 were mentally retarded to a moderate or severe degree and also suffered from epilepsy, while severe but otherwise uncomplicated mental subnormality occurred in 4 children, and in 3 epilepsy was unaccompanied by mental retardation. One child with persistent hemiparesis developed normally otherwise.

Possible contributing factors. In 12 children there were factors operating which may have predisposed to the development of complications, and these are presented in Table IV. One child with possible birth injury had a difficult breech delivery and required intubation.

Of the coincident infections that were a feature in 5 children, upper respiratory tract infections had started 2 days before inoculation in 3 children (from one of whom cytomegalovirus was cultured). Chickenpox appeared 2 weeks before immunization in one child, and from the fifth child who became very ill within 24 hours of inoculation with diarrhoea and dehydration, Coxsackie group A type 7 virus was isolated.
TABLE IV

Possible contributory factors in 12 children

\begin{tabular}{|c|c|c|c|}
\hline & \multicolumn{3}{|c|}{$\begin{array}{c}\text { Interval between inoculation } \\
\text { and reaction }\end{array}$} \\
\hline & $0-24 \mathrm{hr}$ & $1-7 d y$ & 1-2 wk \\
\hline $\begin{array}{l}\text { Previous convulsions } \\
\text { alone } \\
\text { Previous convulsions } \\
\text { + upper respiratory } \\
\text { tract infection } \\
\text { Previous convulsion } \\
\text { + FH of epilepsy in } \\
\text { first-degree relative } \\
\text { FH of epilepsy in } \\
\text { first-degree relative } \\
\text { Developmental delay } \\
\text { + current infection } \\
\text { Recent or current } \\
\text { infection } \\
\text { Perinatal problems } \\
\text { Reaction to previous } \\
\text { DPT }\end{array}$ & $\begin{array}{l}1 \\
2 \\
1 \\
- \\
-\end{array}$ & $\begin{array}{l}- \\
- \\
- \\
2 \\
1 \\
2\end{array}$ & $\begin{array}{l}- \\
- \\
- \\
- \\
-\end{array}$ \\
\hline
\end{tabular}

FH, family history.

\section{Discussion}

It could be argued that any illness in infancy will bear a temporal relation coincidentally to such events as teething and inoculation, and this argument, suitably modified, was applied in considering the occurrence of seizures in the Medical Research Council trials of DPT inoculation (Medical Research Council, 1956). We do not think, however, that the majority of cases we report here represent a chance association because of the clustering of illness in the 7 days after inoculation, and particularly in the first 24 hours (Table III). This clustering is outstanding in the records of the Department of Neurology where there has been a sustained attempt to document both the date of onset of all neurological illness and also the timing of inoculations.

It is assumed that the pertussis component is responsible because the reactions described after DPT inoculation are similar to those seen after pertussis vaccine alone, and also after a natural infection. It is noteworthy that the reactions may occur after any of the inoculations in a series, but most commonly after the first or second. We did not have any evidence of more than one child seriously affected by material from the same ampoule of vaccine, and this has been the experience of others, suggesting an idiosyncratic response rather than a faulty batch.

We do not think that data from our study are of direct help for the debate on the merits of pertussis inoculation because we do not know either the prevalence of natural infection or the frequency of 
inoculation encephalopathy in the population we serve. We suggest, however, that in as many as a third of our patients there were contraindications to inoculation with pertussis vaccine, in that there was a previous history of fits, or family history of seizures in a first-degree relative; reaction to previous inoculation; recent intercurrent infection; or presumed neurodevelopmental defect.

These findings are contrary to the experience of certain authorities. For example, Illingworth (1965) has claimed that he has never seen a complication from DPT inoculation in a child who has had previous convulsions.

The differences between our two views may be due to differences in selection, and the conflict can only be resolved by a careful prospective study of the frequency and circumstances of possible complications. We recommend that pertussis vaccine is withheld from the groups of infants mentioned above, or administration postponed in those recently ill; this policy is unlikely to affect 'herd' immunity significantly.

Finally, we urge the systematic reporting of reactions to all forms of inoculation to the Committee on Safety of Medicines, since we understand that few, if any, reactions to DPT inoculation are notified to the Committee.

\section{REFERENCES}

Berg, J. M. (1958). Neurological complications of pertussis immunization. British Medical fournal, 2, 24.

Byers, R. K., and Moll, F. C. (1948). Encephalopathies following prophylactic pertussis vaccine. Pediatrics, $1,437$.

Cockburn, W. C. (1951). Whooping-cough immunization. Practitioner, 167, 232.
Ehrengut, W. (1966). Keuchhustenschutzimpfung. In Impffibel, p. 243. Schattauer, Stuttgart.

Globus, J. H., and Kohn, J. L. (1949). Encephalopathy following pertussis vaccine prophylaxis. Fournal of the American Medical Association, 141, 507.

Goddard, J. L. (1964). Smallpox, diphtheria, tetanus, pertussis, and poliomyelitis immunization. fournal of the American Medical Association, 187, 1009.

Halpern, S. R., and Halpern, D. (1955). Reaction from DPT immunization and its relationship to allergic children. fournal of Pediatrics, 47, 60.

Hopper, J. M. H. (1961). Illness after whooping-cough vaccination. Medical Officer, 106, 241.

Illingworth, R. S. (1965). Vaccination against whooping-cough. British Medical fournal, $1,1124$.

Köng, E. (1953). Zur Pertussisimpfung und ihren Gegenindikationen. Helvetica Paediatrica Acta, 8, 90.

Madsen, T. (1933). Vaccination against whooping-cough. fournal of the American Medical Association, 101, 187.

Medical Research Council (1956). Vaccination against whooping cough. British Medical fournal, 2, 454

Miller, H. G., and Stanton, J. B. (1954). Neurological sequelae of prophylactic inoculation. Quarterly fournal of Medicine, 23, 1.

Miller, J. J., Jr. (1951). Immunology in the practice of pediatrics. 4. Immunization procedures. Pediatrics, $7,126$.

Provenzano, R. W., Wetterlow, L. H., and Ipsen, J. (1959). Pertussis immunization in pediatric practice and in public health. New England fournal of Medicine, 261, 473.

Sako, W., Treuting, W. L., Witt, D. B., and Nichamin, S. J. (1945). Early immunization against pertussis with alum precipitated vaccine. Fournal of the American Medical Association, 127, 379.

Strøm, J. (1960). Is universal vaccination against pertussis always justified? British Medical fournal, 2, 1184.

Strøm, J. (1967). Further experience of reactions, especially of a cerebral nature, in coniunction with triple vaccination: a study based on vaccinations in Sweden, 1959-1965. British Medical fournal, 4, 320.

Sutherland, J. M. (1953). Encephalopathy following diphtheriapertussis inoculation. Archives of Disease in Childhood, 28, 149.

Vahlquist B., Hesselvik, L., and Ericsson, H. (1954). Active basal immunity and its application to epidemiology. III. Combined immunization against diphtheria, tetanus, and pertussis in infancy. Acta Paediatrica, 43, 15.

Correspondence to Dr. J. Wilson, The Hospital for Sick Children, Great Ormond Street, London WC1N 3JH. 